\title{
Neue Therapie des hereditären Angioödems
}

\author{
Patienten mit hereditärem Angioödem dürfen hoffen: Der monoklonale Antikörper Lanadelumab \\ hemmt spezifisch die Bildung von Kallikrein und hat das Potenzial für eine prophylaktische Therapie.
}

\begin{abstract}
_ Das hereditäre Angioödem geht auf einen Mangel an C1-Inhibitoren zurück. Dieses Protein ist ein wichtiger Regulator der Kaskaden Komplement-Aktivierung, Gerinnung und Kallikrein-Kinin. Die unkontrollierte Bildung von Kallikrein führt zu exzessiver BradykininAusschüttung im Plasma, was sich klinisch als Vasodilatation, Ödembildung und Schmerz äußert. Die betroffenen Patienten bekommen plötzlich auftretende Schwellungen v. a. an den Lippen, im Gesicht und im Rachenbereich, wodurch es zu akuten Notfallsituationen mit Verlegung des Larynx kommen kann.

Die verfügbare Therapie mit Androgenen muss täglich verabreicht werden und hat ein schlechtes Nebenwirkungsprofil - keine gute Option bei einer unvermittelt auftretenden Erkrankung.
\end{abstract}

In einer doppelblinden, placebokontrollierten Phase-Ib-Studie wurde nun der voll humanisierte monoklonale Antikörper Lanadelumab an einer kleinen Zahl von Patienten mit hereditärem Angioödem untersucht. Sie alle hatten mindestens zwei Attacken pro Jahr, seit der letzten waren höchstens sechs Monate vergangen. Vier Patienten erhielten 30 $\mathrm{mg}$, vier Patienten $100 \mathrm{mg}$, fünf Patienten $300 \mathrm{mg}$ und elf Patienten $400 \mathrm{mg}$ der Substanz subkutan injiziert. Die mittlere Halbwertszeit im Plasma betrug etwa zwei Wochen.

Die Dosen von 300 und 400 mg Lanadelumab verringerten die Plasmakonzentration hochmolekularer Kininogene auf Werte, wie sie bei Personen ohne die Erkrankung gefunden werden. Alle Patienten der 300-mg-Gruppe und neun von elf Patienten der 400-mg-Gruppe blieben über 50 Tage hinweg frei von Attacken. In der Placebogruppe waren es dagegen nur drei von elf Patienten. Die Nebenwirkungen beschränkten sich auf Schmerzen an der Injektionsstelle und Kopfschmerzen. Kein Patient beendete die Studie wegen Nebenwirkungen.

- Banerji A et al. Inhibiting plasma kallikrein for hereditary angioedema prophylaxis. N Engl J Med. 2017;376:717-28

\begin{abstract}
KOMMENTAR
Die Probandenzahl ist zu gering, um definitive Schlüsse auf den Wert der Therapie ziehen zu können. Trotzdem sind die Ergebnisse so überzeugend, dass man auf die Auswertung einer derzeit noch laufenden Phase-III-Studie mit Lanadelumab gespannt sein darf.
\end{abstract}

Prof. Dr. med. H. S. FüeßI

\section{Gangrän in Skrotum und Perineum}
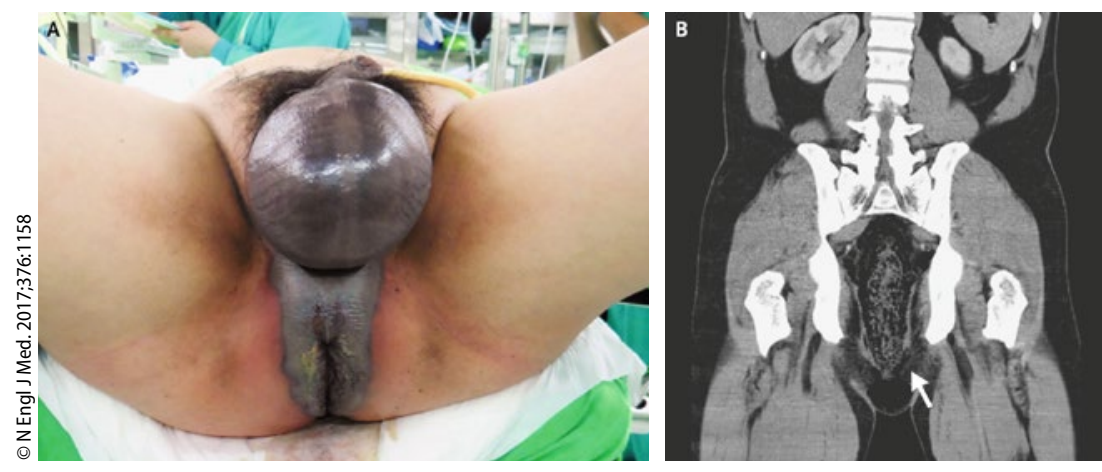

A: Schwellung des Skrotums und der Perinealregion. B: Entsprechendes subkutanes Emphysem, weitere Luft im Bereich des Rektums.

Ein 46-jähriger Mann mit entgleistem Typ-2-Diabetes und alkoholischer Hepatopathie suchte wegen einer schmerzhaften Schwellung des Skrotums und der Perinealregion eine Nothilfe auf. Die Körpertemperatur lag bei $37,7^{\circ} \mathrm{C}$, die Herzfrequenz betrug $130 / \mathrm{min}$ und der Blutdruck $97 / 61 \mathrm{mmHg}$. Die Haut im Bereich des Skrotums und des Perineums war dunkel verfärbt und machte einen nekro- tischen Eindruck mit verhärteten Arealen und Knistern (Abb. A). Im CT des Abdomens zeigte sich ein subkutanes Emphysem des Skrotums und der perinealen Faszie mit zusätzlicher Luft im pararektalen Gewebe und der Rektumwand (Abb. B). Man stellte die Diagnose einer Fournier-Gangrän, einer nekrotisierenden Fasziitis des Perineums. Es handelt sich um eine seltene, fulminante, lebensbedrohliche Infektion, die v. a. bei älteren Männern sowie Männern mit Diabetes und chronischer Lebererkrankung auftritt.

Der Patient unterzog sich einer laparoskopisch geführten perinealen Resektion. Histologisch fanden sich im nekrotischen Gewebe zahlreiche gasgefüllte Taschen und eine leukozytäre Infiltration. Der Patient wurde zusätzlich mit Breitspektrum-Antibiotika behandelt. Etwa drei Wochen nach dem Eingriff erfolgte eine Spalthaut-Transplantation in dem Bereich des Perineums. Der Patient wurde mit einer dauerhaft angelegten Kolostomie entlassen.

Prof. Dr. med. H. S. Füeßl

- Huang CS. Fournier's gangrene. N Engl J Med. 2017;376:1158 